\title{
Afinal, do que depende a satisfação do revisor para a sua atividade nacomunicação científica?
}

\author{
Fábio Frezatti \\ https://orcid.org/0000-0002-5927-022X | E-mail: frezatti@usp.br \\ Diógenes de Souza Bido \\ https://orcid.org/0000-0002-8525-5218 | E-mail:diogenesbido@yahoo.com.br
}

\section{Resumo}

Objetivo: Identificar o que estimula ou inibe a satisfação do revisor no desempenho de suas tarefas, a partir da abordagem seminal de Katz e Kahn (1970) em que o conflito de função e a ambiguidade de função são analisados no que se refere ao papel do revisor.

Método: A coleta de dados foi realizada por meio de surveycom a comunidade de pesquisa de contabilidade e administração, resultando em 153 questionários válidos. Para o tratamento dos dados, foi utilizada a estatística descritiva e a modelagem de equações estruturais.

Resultados: O posicionamento do periódico em rankings, como Qualis e JCR,está entre os aspectos que mais afetam favoravelmente a satisfação do revisor. A ambiguidade de função impacta negativamente a satisfação do revisor. Os elementos de conflito de função não foram identificados como afetando negativamente a satisfação.

Contribuições: $\mathrm{O}$ revisor de artigos acadêmicos desempenha uma atividade fundamental na construção do conhecimento por proporcionar o aperfeiçoamento e a confiabilidade da publicação, por isso, entender como a motivação, a ambiguidade de função e o conflito de função impactam a satisfação do revisor pode aumentar o potencial de gestão pelos editores de periódicos acadêmicos e valorizar o papel do revisor, principalmente no momento em que os periódicos acadêmicos da área se posicionam de forma competitiva frente aos periódicos internacionais.

Palavras-chave: Revisor. Conflito de função. Ambiguidade de função. Satisfação do revisor. 


\section{Introdução}

Existem vários atores presentes na comunicação do conhecimento, quais sejam os membros de conselho editorial, os editores, revisores de artigos, os assistentes editoriais técnicos, fornecedores de serviços de editoração, revisão, versão e tradução, e os leitores. É um ecossistema complexo em que os agentes (o autor, o revisor e o leitor) se destacam por serem complementares e interligados na publicação acadêmica, sendo fundamentais para a percepção da extensão e qualidade do sistema de comunicação do conhecimento. A combinação entre os três proporciona o relacionamento que a comunidade demanda para que o conhecimento seja criado e comunicado com credibilidade (Moizer, 2009).

Entre os revisores e autores, o blindreview prevalece evitando o constrangimento de saber quem fez o quê. Atrás do blindreview, o revisor se torna poderoso, muito embora seu papel seja consultivo durante o processo de seleção e de aperfeiçoamento dos artigos (Moizer, 2009; Berk et al., 2017). Mesmo assim, a relação entre os três agentes é desequilibrada, desproporcionalmente diferente e, quase sempre, tensa. Dizer para o revisor que a sugestão feita é inadequada, inútil e pretensiosa não é algo que possa parecer possível no sistema de avaliação de artigos acadêmicos contemporâneos.

Por outro lado, pela maneira como a comunidade opera, um revisor pode utilizarem suas pesquisas um artigodo qual ele foi o revisor, assim como um autor pode revisar um artigo de um revisor, ou um leitor ser chamado para revisar um novo trabalho de um autor que ele costuma utilizar para novos conhecimentos. Resumindo, a combinação colaborativa é dinâmica, pouco controlávele o modelo de publicações demanda a participação intensa dos três agentes com alguma percepção de ganha/ganha. Esses tipos de tensões podem trazer forte impacto sobre o desempenho dos agentes, criando desgastes que afetem a disposição de desenvolverem seus papéis.

A lacuna encontrada é a ausência de pesquisas, principalmente no Brasil e na área, sobre esse relacionamento, mormente no que se refere à satisfação dorevisor em desenvolver o seu trabalho, fundamental para a comunicação da inovação. A importância de entender o convívio entre os três agentes em diferentes ambientes demanda esse tipo de pesquisa de campo, pois a área convive com ambientes com diferentes níveis de maturidade, conhecimentos e expectativas em termos de relacionamento entre os agentes.

O objetivo da pesquisa consiste em entender suas pressões e recompensas, estas últimas traduzidas pelo conceito de satisfação de ser revisor. Nesse sentido, a pesquisa inova ao utilizar uma abordagem do conflito e da ambiguidade de função sobre a satisfação (Katz \& Kahn, 1970), até então utilizada dentro do ambiente empresarial, mas, não, no ecossistema editorial. Com isso, a contribuição consiste em proporcionar aos agentes participantes do ecossistema de publicações melhor entendimento sobre elementos que impactam o papel do revisor, permitindo ações da parte do editor sobre a importância da clareza das instruções, valorização de elementos que proporcionem a fidelização dos revisores, não apenas à aceitação do trabalho, mas esforço pela qualidade da análise propriamente dita. O impacto dessas contribuições está ligado ao potencial de melhoria da qualidade dos artigos aceitos e publicados e, em alguma dimensão, aumento das citações dos artigos.

A questão orientadora da pesquisa é: Quais são os elementos que afetam positivamente e negativamente a satisfação dos revisores envolvidos na comunicação das pesquisas acadêmicas?

Para respondê-la, foi desenvolvido um modelo conceitual com três preditores da satisfação do revisor: a motivação, a ambiguidade de função e o conflito de função, que foi testado por meio da modelagem de equações estruturais a partir de dados obtidos com os pesquisadores/revisores da área de contabilidade e administração. Os resultados não confirmaram o impacto dos conflitos de função, mas confirmaram os impactos da ambiguidade de função $(-0,233, \mathrm{p}<0,01)$ e da motivação $(0,387, \mathrm{p}<0,01)$, resultando em um $\mathrm{R}^{2}$ ajustado igual a $23,3 \%$. 


\section{Os Agentes na Comunicação do Conhecimento}

O leitor é usuário final quando recebe e usa aquilo que aprende na área de ciências sociais aplicadas. Entretanto, pode também ser o usuário que filtra o conhecimento para que ele possa ser aplicado. Afinal, pela perspectiva da área acadêmica, a aplicação no campo que proporcionou o corpo para o desenvolvimento da pesquisa, nem sempre é uma preocupação relevante. Contudo, existe a expectativa de benefício para os leitores, de uma comunicação que possa ser dimensionada tanto no que se refere a implementações das inovações como aperfeiçoamento do ambiente educacional e gerencial (Van De Ven \& Johnson, 2006).

O autor proporciona, por meio de uma abordagem metodológica aceita pela mesma comunidade, comunicação de inovação pela pesquisa desenvolvida, muitas vezes, desafiadora e complexa para os revisores, e que pode acarretar a rejeição do artigo pelo editor(Berk, Harvey, \& Hirshleifer, 2017). A comunicação dentro da comunidade é feita por meio dos periódicos e passa por um processo de legitimação de que o conhecimento oferecido tem relevância, contribuição e que foi desenvolvido seguindo a metodologia adequada. Ele tem que proporcionar clareza quanto ao seu ponto de vista sobre o tema tratado (Reuber, 2010)e ele depende do posicionamento e apoio proporcionado pelos revisores. Dessa forma, o autor é usuário e fornecedor do conhecimento à medida que se baseia em conhecimentos comunicados para poder fazê-lo também. Em um estudo na área de economia, apurou-se que os artigos atuais, quando comparados com os artigos de algumas décadas atrás, são mais extensos, provavelmente tanto pela complexidade dos problemas tratados como pela necessidade de atender demanda dos revisores ou de maior clareza (Berk et al., 2017). Uma contribuição efetiva de um revisor vai impactar a vida do autor em termos de citações e prestígio.

Os editores são responsáveis pela definição tanto da direção (o que se fará) como da profundidade (até que ponto se avançará) das pesquisas, zelando para que a relação ótima entre ambas se alcance a partir de um equilíbrio entre as três lógicas: terminologia, epistemologia e metodologia (Trzesniak, Plata-Caviedes, \& Córdoba-Salgado, 2012). Entre as atividades necessárias para que desempenhem suas funções, a escolha dos revisores é uma das mais relevantes. Em várias áreas do conhecimento, tem sido percebido que a quantidade de artigos gerados é muito grande perante o potencial de acréscimo de conhecimento (Anderson, 1997). Muitos artigos sem contribuição têm sido gerados por motivos diversos ao da comunicação de alguma inovação, e isso aumenta o trabalho dos editores e revisores, sem benefício para os leitores. Espera-se que os editores dos periódicos proporcionem aos autores informações para que eles sejam "educados" em termos de procedimentos, inclusive éticos (Anderson, 1997).

Por fim, o revisor é o agente que analisa, refina, propõe alterações nos artigos a publicar. Normalmente convidado pelo editor, deve ser confiável pela ótica do grupo editorial e proporcionar apoio aos editores para que estruturem os documentos de comunicação das decisões (Sharma, 2016).

Em algumas áreas, os autores sugerem nomes de revisores de seus artigos (Rivara, Cummings, Ringold, Bergman, Joffe, \& Christakis, 2007), mas não é a regra, já que a neutralidade é relevante e sua garantia pode ser vista de formas diferentes nas várias áreas de conhecimento. Moizer (2009) indica que o papel do revisor consiste em avaliar os manuscritos quanto à competência profissional, qualidade de apresentação, relevância do assunto e a importância da contribuição para a literatura. Espera-se dele uma abordagem, ao mesmo tempo crítica e construtiva (Rigo \& Ventura, 2019).

A revisão é uma atividade colaborativa que atrai os pesquisadores em função de vários motivos dependendo da forma como os editores se utilizam do relacionamento para atrair bons revisores que, em muitos casos, praticamente reconstroem artigos, dialogando com os autores e recomendando alterações. Em última análise, o papel do revisor é consultivo e a decisão final sobre aceitação, ou não, do artigo é uma responsabilidade do editor (Coniam, 2012). A prática de avaliar o desempenho dos revisores já é bastante comum em várias áreas, existindo, inclusive, rankings para isso (Rivara et al., 2007). 
Normalmente a rotina do periódico inclui desgastes entre os agentes, como situação em que o autor não aceita uma recomendação de um revisor e a considera rude, ou então uma denúncia de uma questão ética, movimentando o revisor para que faça um parecer (Sharma, 2016). O trabalho de Berk, Harvey e Hirshleifer (2017) indica uma insatisfação dos revisores no que se refere a avaliar artigos que considerariam adequados à rejeição imediata e que são enviados a vários revisores. Esse é um problema de entendimento dos limites de responsabilidade do revisor. De qualquer forma, do trabalho dos revisores surge o apoio para que o editor se posicione na aceitação, ou não, do artigo acadêmico (Berk et al., 2017), demandando da parte daquele confiança na análise e posicionamento crítico.

É de fundamental importância que os revisores tenham equilíbrio entre o desejo de um artigo perfeito e um artigo possível com contribuição (Berk et al., 2017). Em termos de trabalho, alguns periódicos demandam dos revisores uma ou duas revisões (Berk et al., 2017) e outros mais do que isso, o que ocasiona carga de trabalho substancial, bem como possível sensação de potencial antagonismo, agora não apenas entre revisor e autor, mas potencial também entre revisor e editor. O que dificilmente é explorado, e nem sempre percebido, é o potencial aprendizado que todos os agentes têm com o processo editorial.

Uma das propriedades relevantes do processo de revisão decorre de poder proporcionar aos autores feedback para que possam aperfeiçoar suas pesquisas e respectivas comunicações (Coniam, 2012). Com isso a habilidade de comunicação, embora filtrada pelo editor, deve ser uma característica de um bom revisor. Na verdade, muito mais do que isso, não existe na área um "código de ética" universalmente consolidado e consistente no que se refere às responsabilidades do revisor(Bailey, Hermanson, \& Louwers, 2008). Algumas pesquisas identificam percepções positivas e negativas por parte dos autores no que se refere ao desempenho e atuação dos revisores (Bailey et al., 2008).

Oler e Pasewark (2016) discutem os papéis dos revisores que, ao mesmo tempo, lidam com duas diferentes e nem sempre confluentes dimensões, que são: (1) ajudam os editores de revistas a cumprirem seu papel de "gatekeeper" e (2) ajudam os autores na melhoria da sua investigação. Com isso a atividade é altamente conflitante e demanda constante posicionamento consistente do revisor e os autores citados indicam problemas de agência, porque os revisores são anônimos aos autores e, muitas vezes, há escassez de revisores qualificados (Gilmore, Carson, \& Perry, 2006), o que torna o processo de revisão vulnerável, pois alguns revisores podem acreditar que podem exigir dos autores que façam o que eles querem (Moizer, 2009). Muito embora o seu papel seja entendido como relevante, questionamentos existem em relação ao processo em que ele é envolvido e à sua eficácia (Bailey et al., 2008). Ainda assim, apesar das dificuldades, não se percebe nenhuma alternativa melhor ao processo de revisão tradicional e, no momento, nenhuma revista relevante propôs um substituto.

Acadêmicos têm um interesse em garantir que o processo de revisão sejaeficiente e eficaz, destacando a importância de realizar revisões de qualidade. Revisões feitas e comunicadas de maneira não adequada prejudicam a reputação de uma revista, frustram editores e desencorajam novas pesquisas. Em contraste, as boas críticas reforçam a reputação de uma revista, tornam o trabalho do editor mais fácil e incentivam pesquisas inovadoras e interessantes(Oler \& Pasewark, 2016).

Dos três agentes, o revisoré o que tem menos a ganhar e é o que tem menor reconhecimento pelo seu trabalho e contribuição. Embora seja muito relevante para a construção do conhecimento e demande tempo e energia dos revisores, a tradição da maior parte dos periódicos leva em conta o não pagamento pelo trabalho (Oler \& Pasewark, 2016). Nessas condições, entender o que pode afetar a satisfação do revisor se torna fundamental para a sua fidelização no sistema de comunicação acadêmica. 


\section{Conflito de Função}

No trabalho seminal de Katz e Kahn (1970, p.415), foi considerado que a satisfação no trabalho é a percepção de um indivíduo quanto à sua situação atual como responsável de um cargo organizacional, assim comopela percepção que deriva do entendimento sobre o conteúdo dos requerimentos exigidos para desenvolver aqueles processos de trabalho pelos quais ele é responsável. Assim sendo, a satisfação é algo que permite que os revisores desenvolvam seus trabalhos de maneira perene, continuada, e os conflitos vivenciados pelo revisor podem fazer com que a satisfação não ocorra.

O conflito de função surgeda ocorrência de dois ou mais requerimentos de função de maneira que um provoque dificuldades para o desempenho ou mesmo a impossibilidade de atingir o requerimento do outro (Katz \& Kahn, 1970; Fisher,1995).

Operacionalmente (Rizzo, House, \& Lirtzman, 1970), o conflito de funçãopode ser entendido em decorrênciada congruência/incongruência ou compatibilidade/incompatibilidade entre: (i) os padrões ou valores do indivíduo e o comportamento definido para uma função, (ii) o tempo, os recursos ou as capacidades do indivíduo, e o comportamento definido para desempenhar uma função, (iii) as várias funções que um únicoindivíduo deve preencher, e (iv) os vários inputs organizacionais inseridos nas políticas, regras e sugestões das pessoas ligadas com a função incumbente ao indivíduo. Um exemplo de conflito de função, item ii acima, um dado revisor recebe um convite para analisar um artigo com tempo exíguo demais para a complexidade que ele vai enfrentar.

No caso desta pesquisa, a função de revisor pode ser conflitante com a de autor e do editor por dominarem o mesmo tipo de conhecimento, nem sempre de forma harmônica. Como exemplo (tipo iv acima), podemos citar a análise de um artigo que pretenda discutir a melhor alternativa de método de custeio para pricing por dois revisores com larga experiência em custos e que tenham diferentes entendimentos sobre o método direto e a variável.

Mihalek (1989) especifica três oportunidades em que o conflito de função pode ocorrer. A ocorrência do conflito de função pode surgir em ocasiões em que mudanças provoquem situações em que háo estabelecimento de metas organizacionais com incongruência de uma delas sobre outra. Isso pode acontecer quando um profissional tem uma meta relacionada a tempo de desenvolvimento de uma atividade e outra referente à qualidade de uma mesma atividade. Se forem muito desafiadoras, o conflito de função pode ser uma realidade para o profissional. No caso do revisor, um texto complexo ou mesmo de difícil compreensão pode tomar muito tempo, desafiando a sua capacidade de ser eficiente. Diferentemente de operar dentro de uma empresa, por exemplo, as estruturas de apoio no ecossistema editorial são mais fluidas, flexíveis e, em alguns momentos, vagas.

Outra forma de encontrar o conflito de função (Tarrant, 2008) surge quando novas funções surgem na atividade profissional, demandando perfil profissional diferente do que está acostumado. Analogamente, a exigência de novas capacitações para o desempenho de uma dada função provocará impacto similar. Isso pode ser ainda mais impactante se o profissional não tiver uma formação profissional que permita adaptação no desenvolvimento da carreira. Nesta pesquisa esse elemento pode aflorar quando alguém convidado para analisar uma perspectiva teórica tem que levar em conta uma técnica estatística, por exemplo, com a qual não sente conforto. Moizer (2009) indica uma realidade importante, pois o revisor aprende fazendo, o que torna o feedback fundamental para o seu aperfeiçoamento. Afinal, qual o limite da responsabilidade e o que o revisor entende como possível de deixar claro para o editor?

$\mathrm{O}$ autor quer publicar o mais rápido possível e gostaria que o seu trabalho não fosse profundamente alterado pelo revisor. Este último, por sua vez, não tem compromisso com a estabilidade do que foi oferecido e a sua lógica consultiva ocorre porque é reconhecido como alguém que conhece, estuda e sabe como contribuir para o acréscimo do conhecimento, que é a inovação. 
Um revisor muito exigente ou com expectativa de transformar o artigo em algo premiado pode desafiar o autor fora da expectativa que ele teria (Moizer, 2009). Por outro lado, o convívio do revisor com os periódicos afeta a sua postura e a forma de olhar os seus próprios artigos: uma chance de aprendizado não estruturado. Uma outra ocorrência possível afetando a comparabilidade e motivação: a partir da rejeição do trabalho de um revisor, afetando o seu humor quanto à revisão de um artigo que considere inferior ao seu, por exemplo.

\section{Ambiguidade de Função}

A ambiguidade de função é a incerteza sobre o que o responsável por uma atividade específica deveria fazer (Kahn, Wolfe, Quinn, Snoek, \& Rosenthal,1964;Fichter, 2010). Essa incerteza pode ser materializada por falta de definições acerca das responsabilidades, expectativas e comportamentos esperados de um executivo em um cargo, ou a falta de informação sobre a abrangência das suas funções, que podem criar ambiguidade de função (Singh \&Rhoads,1991).

Fisher (1995) discute e aperfeiçoa o tratamento dos possíveis estimuladores da ambiguidade de função, mantendo (i) as expectativas relevantes e esperadas sobre o desempenho de um cargo, mas ampliando com a inclusão da importância dos direitos, deveres e responsabilidades deste,(ii) incluindo as atividades imprescindíveis para cumprir eficazmente as funçõespróprias do cargo, bem como os passos ou a melhor forma para realizá-lo, (iii) as consequências da execução e da não execução das funções, (iv) o comportamento que é recompensado ou punido, a natureza das recompensas e punições, ou o comportamento que é satisfatório ou frustrante no desempenho da função, e finalmente (v) as oportunidades para o avanço.No caso desta pesquisa, a falta de clareza, extensão de uma análise e mesmo o escopo podem trazer estímulos para a percepção de ambiguidade.

No caso do relacionamento dos três agentes, ao enviar o artigo para o periódico, o autor não consegue avaliar que tipo de recomendação do revisor seria indiscutível e qual demandaria uma justificativa para a sua manutenção. O revisor pode vivenciar um enorme esforço, argumentando que o artigo é inadequado e ver o editor dar outra oportunidade para os autores, frustrando suas expectativas. Isso pode acontecer quando ignora que o seu papel principal é consultivo. Um novo revisor para analisar um trabalho que passa pelo impasse de diálogo truncado pode trazer, tanto ao revisor como ao autor, a sensação de que o trabalho nunca termina, o que aumenta a tensão no processo, impactando a ambiguidade de função quanto à expectativa de responsabilidade ou de real impacto sobre o processo.

Particularmente no que se refere aos direitos, deveres e responsabilidades do revisor, quando um editor insiste em rever mais uma vez dado artigo,o revisor pode se sentir pouco valorizado,dado seu esforço para analisar e propor a rejeição de um trabalho. Trata-se de um exemplo de expectativa quanto ao resultado do trabalho do revisor, que esperaria que a sua recomendação de rejeição fosse efetivada. Provavelmente essa tensão irá afetar a resposta de um futuro convite para revisar um trabalho. Por outro lado, poderia também provocar uma reflexão sobre o revisor em termos de ajustar a sua forma de valorizar diferentes elementos de um dado trabalho, percebido pelo editor.

\section{Conflito, Ambiguidade de Função e Satisfação}

Várias pesquisas relacionaram conflito e ambiguidade de função com satisfação no ambiente de trabalho. Gregson e Wendell (1994) estudaram a relação entre as variáveis, autoestima, conflito de função, ambiguidade de função e satisfação no trabalho em uma amostra de 216 executivos. Como conclusão do estudo inferiu que o conflito e a ambiguidade de função se relacionaram direta e negativamente com a satisfação no trabalho em $-0,19$ e $-0,57$, respectivamente. 
Outra pesquisa realizada por Karadal e Cuhadar (2008, pp.179-180), com uma amostra de 219 colaboradores de empresas do setor público e privado da Turquia, evidenciou que a ambiguidade e o conflito de função se relacionaram negativamente com a satisfação no trabalho em $-0,34$ e $-0,37$, respectivamente, mas o comprometimento organizacional mostrou uma relação positiva e forte de 0,67 com a variável satisfação no trabalho. Segundo os autores, estes resultados são consequência de um mau gerenciamento no estabelecimento de posições, delegação de autoridade, definição de responsabilidades e funções, que consequentemente criam esses dois tipos de tensões.

Por sua vez, Tarrant (2008), a partir de uma amostra de profissionais da área de enfermagem, ao assumirem novas responsabilidades nos seus cargos, encontrou moderados níveis de conflito e ambiguidade de função em relação àsatisfação no trabalho. As causas dos níveis de tensões derivaram das percepções de reconhecimento e oportunidade de participação em novas atividades.

Montgomery (2011)tratou osconstrutos relacionados com conflito e ambiguidade de função nas organizações, em um cenário organizacional onde os trabalhadores indicaram ser responsáveis por diversas funções, e onde eles citaram não ter certeza de como equilibrar as diversas necessidades organizacionais a eles requeridas, as quais competiam estruturalmente em função de prioridades e objetivos solicitados por mais de um gestor imediato à sua posição.Concluiu que oconflito e a ambiguidade de função se relacionaram negativamente com a satisfação no trabalho,corroborando as pesquisas anteriores.

Palomino e Frezatti (2016) trataram o tema no que se refere ao controller das organizações brasileiras e as conclusões indicaram que controllers brasileiros percebem conflito e ambiguidade de função quando desempenham suas funções. A satisfação no trabalho dos controllers é afetada com maior intensidade pela ambiguidade de função do que pelo conflito, mas, apesar de perceberem essas duas tensões, os executivos encontram-se moderadamente satisfeitos com suas atuais condições de trabalho.

A satisfação entra no ambiente de pesquisa, analogamente ao que ocorre no ambiente organizacional (Katz e Kahn, 1970) como elemento que permite tratar a recompensa pelo envolvimento, na leitura, na revisão ou mesmo na autoria. Baixa satisfação pode trazer consequências da não aceitação de um convite para analisar uma pesquisa ou mesmo fazê-lo de forma pouco compromissada (Berk, Harvey\& Hirshleifer, 2017). Particularmente no que se refere à função do revisor, esse quesito se torna fundamental, pois muito da qualidade das publicações depende do envolvimento e esforço do revisor.

Existe uma grande diferença no tratamento do tema dentro de uma organização voltada para resultados e uma entidade que depende de trabalho colaborativo de pessoas que, muitas vezes, jamais se encontrarão. Uma revisão de um artigo pode demandar algumas horas ou mesmo semanas, dependendo da complexidade e escopo de análise pretendida. Trata-se de relacionamento colaborativo que não tem dimensão de tempo nem acordo formal de quantidade a ser entregue. Menos ainda em termos de carreira formal, além de uma dissipação de hierarquia e obrigação de responder por algo que é aceito caso a caso, à medida que o editor convida um revisor para cada artigo, dependendo da sua habilidade. Um revisor sênior ou um autor seminal têm reconhecimento na comunidade que os abriga, mas se trata de algo que está mais na percepçãodo que em um modelo formal.

\section{Motivação para Aceitar a Função de Revisor}

A aceitação e a vivência na função do leitor, do autor e do revisor decorrem de algum tipo de motivação (adaptado de Katz e Kahn, 1970),relacionada a aspectos que possam proporcionar a satisfação pelo exercício da função. Alguns dos elementos foram reconhecidos na literatura de forma objetiva (síntese na Tabela 1 e detalhamento no Apêndice 1). A metodologia Delphi foi aplicada para validar as assertivas que permitem captar os conceitos que operacionalizam os elementos dos construtos, tanto referentes a conflito de função como ambiguidade de função, como motivação e também satisfação. Foram convidados pesquisadores com experiência na realização de pesquisas e também atividade de revisão de artigos acadêmicos. O detalhamento dos elementos e dos conteúdos foi disponibilizado no Apêndice 1. 
Tabela1

Critérios considerados na estruturação do questionário

\begin{tabular}{l}
\hline \multicolumn{1}{c}{ Elemento e referencial } \\
\hline Avaliação externa: Trzesniak,Plata-Caviedes e Córdoba-Salgado (2012); Harzing e Van der Wal(2008) \\
\hline Avaliação qualitativa: Engers e Gans (1998) \\
\hline Características do artigo: Engers e Gans (1998); Coniam (2012) \\
\hline Percepção de benefício: Tarrant (2008); Engers e Gans (1998); Cabral (2018); Katz e Kahn (1970) \\
\hline Apoio e interesse de relacionamento: Moizer (2009) \\
\hline Fonte: elaborado pelos autores.
\end{tabular}

Levando em conta a necessidade da customização dos elementos para o tema da pesquisa, foi desenvolvido trabalho adicional para caracterizar e confirmar os agrupamentos. Osagrupamentos de critérios foram criados a partir de identificação por parte de pesquisadores elegitimados por uma sequência de pareceres de membros da comunidade, inspirados na técnica Delphi (Wright \& Giovinazzo, 2000), na qual um grupo de especialistas opinou. No presente caso, os papéis de coordenação e de conhecedores foram desempenhados, respectivamente, pelos autores e por cinco pesquisadores convidados, submetidos ao processo em sequência.Uma vez que o primeiro especialista opinou, a partir de uma base inicial de critérios básicos, o segundo especialista recebeu o novo conjunto, com as alterações proporcionadas pelo primeiro grupo e assim sucessivamente. A escolha dos pesquisadores levou em conta a experiência como autores, revisores e leitores de publicações acadêmicas.

Os agrupamentos estabelecidos foram os seguintes (Apêndice 1):

\section{Avaliação externa}

Os agentes são motivados a aceitar os seus papéis, quando os periódicos têm avaliação externa favorável de algum ente ou instituição que tenha legitimidade legal ou da comunidade (Trzesniak, PlataCaviedes e Córdoba-Salgado, 2012). Pode significar ranking do QUALIS, inclusão na lista do JCR, do SCIELO, SCOPUS ou do SPELL. Trata-se de um critério que deve trazer benefício relativamente "objetivo" quanto à qualidade do esforço despendido (Harzing \& Van der Wal, 2008).

\section{Avaliação qualitativa}

Decorre da percepção do agente, independentemente da avaliação externa, de que existe mérito em desenvolver a função em periódicos da comunidade.

\section{Características do artigo}

A motivação do agente pode decorrer de características intrínsecas dos periódicos.

Algumas delas são: clareza, simplicidade da comunicação, conteúdos com alta sofisticação, por exemplo; língua em que a comunicação seja oferecida, tais como inglês, português e espanhol, entre outras. Caberia aí também a identificação com a linha editorial ou amplitude ontológica.

\section{Percepção de benefício}

A motivação do agente pode decorrer da percepção de algum tipo de benefício. Exemplos como algum tipo de reconhecimento, monetário ou premiação, periódicos em que seja possível aprender algo, periódicos em que seja possível ensinar algo, podem ser considerados.

\section{Apoio e interesse de relacionamento}

A motivação do agente pode decorrer da percepção da possibilidade de apoiar uma instituição ou pessoa. Dentre vários exemplos, podem ser mencionados: confiança no corpo editorial do periódico, relacionamento com o corpo editorial, intenção de publicar no periódico, já ter publicado no periódico. 


\section{Modelo Conceitual e Hipóteses}

Em decorrência do construto demandado para tratar o problema de pesquisa, o modelo conceitual é apresentado na Figura 1:

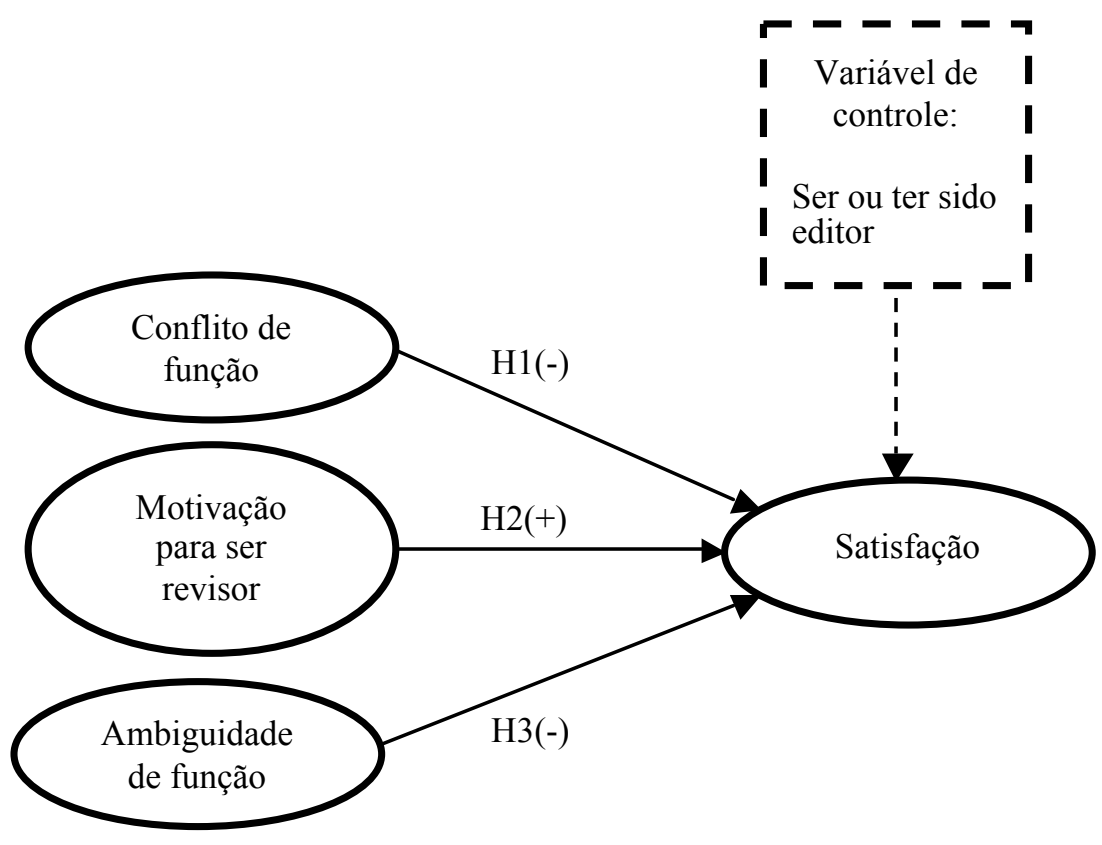

Figura 1. Modelo conceitual da pesquisa.

Fonte: elaborado pelos autores.

Para estruturar a pesquisa e sua análise, as hipóteses desenvolvidas foram as seguintes:

- H1. O conflito de função afeta negativamente a satisfação de ser revisor de artigo de periódico acadêmico.

É relacionada com o conflito de função afetando a função dorevisor. A estrutura de assertivas que representam as variáveis decorrem do referencial (Montgomery, 2011; Karadal \& Cuhadar, 2008, pp.179180; Gregson \& Wendell, 1994; Palomino \& Frezatti, 2016).

- H2. A motivação afeta positivamente a satisfação de ser revisor de artigo de periódico acadêmico.

Relacionada com a motivação para que a função seja aceita, afetando a função do revisor (Katz \& Kahn, 1970; Gregson \& Wendell; 1994); Palomino \& Frezatti, 2016)

- H3. A ambiguidade de função afeta negativamente a satisfação de ser revisor de artigo de periódico acadêmico.

Relacionada com a ambiguidade de função afetando a função do revisor. A estrutura de assertivas que representam as variáveis decorre do referencial (Montgomery, 2011; Karadal \& Cuhadar, 2008, pp.179180; Gregson \& Wendell, 1994; Palomino \& Frezatti, 2016). 


\section{Coleta e análise dos dados}

\subsection{Coleta dos dados}

A identificação da população foi parte relevante do processo de pesquisa,pois não existe uma fonte disponível que pudesse ser utilizada de pronto. Os autores a construíram a partir da combinação de bases de dados de congressos e de periódicos. No total foram identificados e enviados convites por e-mail para cerca de 8.000 pesquisadores atuantes em periódicos e congressos de contabilidade e administração. A coleta de dados ocorreu entre junho a agosto de 2017. Foram recebidas 300 respostas e, em função da eliminação das respostas incompletas, foram consideradas 153 como válidas. O tratamento dos dados faltantes (missingvalues) foi feito da seguinte maneira: mesmo após a eliminação dos casos que continham, mas de $14 \%$ de dados faltantes, os indicadores conf_r_4 e conf_r_5 ainda apresentavam 18\% e 16\% de dados faltantes e após algumas tentativas de imputação, suas cargas fatoriais também eram baixas, por isso, foram excluídos do modelo. Para os demais casos e variáveis, o teste de Little indicou que a distribuição dos dados faltantes era MCAR (Missing Completelyat Random), o que permitiu a imputação da média (Little, 2013). Como consequência da construção exposta, a amostra é por conveniência.

Temos aqui uma pesquisa quantitativa desenvolvida por meio de levantamento aplicado à comunidade de pesquisa de contabilidade e administração, sendo que o questionáriofoi elaborado a partir dos construtos disponíveis (conflito de função e ambiguidade de função), validados em português por Palomino e Frezatti (2016) e o complemento referente à motivação para ser revisor, com as variáveis de aderência validada por pesquisadores da área, por meio do Delphi (Apêndice 1).

Quanto ao pré-teste, foi desenvolvido a partir do envio do questionário para cinco pesquisadores com atuação prévia tanto em termos de serem autores como terem sido revisores de artigos acadêmicos. A validação de revisores levou em conta que a atuação tenha ocorrido em periódicos de contabilidade e/ou administração. $\mathrm{O}$ argumento para tal prática está ligada ao fato de que os revisores, independentemente da titulação (Contabilidade, Administração, Economia, Engenharia de Produção, Psicologia, Matemática etc., em uma dimensão temporal, podem atuar em periódicos tanto de Contabilidade como Administração). Além disso, temos segmentos das áreas que podem ser encontradas tanto em Contabilidade como Administração (Finanças, Pública, Gestão etc.). Esse procedimento também se aplicou na estruturação do Delphi e no convite aos respondentes. Os elementos considerados pelos convidados foram:(i) potencialidade de resposta com e sem a identificação do respondente, (ii) questões ligadas à clareza do questionário, (iii) outras alternativas de itens que poderiam motivar/afetar as ações. Foi aguardado o retorno, foram ajustados os elementos considerados passíveis de sê-lo e enviado a outro pesquisador, de outro centro de pesquisa e estado, que não sugeriu novas revisões.

No total foram recebidos 153 questionários válidos, com as características apresentadas na Tabela 2, destacando-se que 55 (36\%) são ou já foram editores de periódicos e 77 (50\%) são doutores que atuam na docência e pesquisa, portanto, têm experiência suficiente para responderem adequadamente o que foi questionado. 
Tabela 2

Formação e atuação dos respondentes

\begin{tabular}{lcc}
\hline \multirow{2}{*}{ Formação e Atuação } & \multicolumn{2}{c}{ Total } \\
\cline { 2 - 3 } & $\mathrm{n}$ & $\%$ \\
\hline Editor (foi ou é) & 55 & $36 \%$ \\
\hline Doutor(a) atuando em docência & 92 & $60 \%$ \\
\hline Doutor(a) atuando em pesquisa & 85 & $56 \%$ \\
\hline Doutor(a) atuando em docência e pesquisa & 77 & $50 \%$ \\
\hline Doutorado obtido fora do país & 5 & $3 \%$ \\
\hline Doutorado obtido fora da instituição onde atua & 47 & $31 \%$ \\
\hline Mestre atuando em docência & 23 & $15 \%$ \\
\hline Mestre atuando em pesquisa & 7 & $5 \%$ \\
\hline Doutorando & 25 & $16 \%$ \\
\hline Mestrando & 3 & $2 \%$ \\
\hline Total & 153 & $100 \%$ \\
\hline
\end{tabular}

Fonte: Resultados da pesquisa.

Os modelos de equações estruturais podem ser estimados por métodos baseados em covariâncias com softwares como AMOS, LISREL e MPLUS, mas as principais restrições ao seu uso no presente caso são: (i) complexidade do modelo, com VL de segunda ordem, (ii) presença de VL formativa (Hair Jr. et al., 2016), por isso, foi decidido estimar o modelo por mínimos quadrados parciais (PLS-SEM), com o software SmartPLS 3 (Ringle, Wende, \& Becker, 2015).

\subsection{Avaliação do modelo de mensuração}

A motivação para atuar como revisor (MOT_REV) foi modelada como uma variável latente de $2^{\text {a }}$ ordem formativa, que foi mensurada por cinco Variáveis Latentes $(\mathrm{VL})$ reflexivas de $1^{\text {a }}$ ordem (Apêndice 1), a saber:

- mot_rev_CAE = critérios de avaliação externa;

- mot_rev_CAIR = critérios de apoio e interesse de relacionamento;

- mot_rev_CAQ = critérios de avaliação qualitativa;

- mot_rev_CCA = critérios de características do artigo (idioma);

- mot_rev_CPB = critérios de percepção de benefício. 


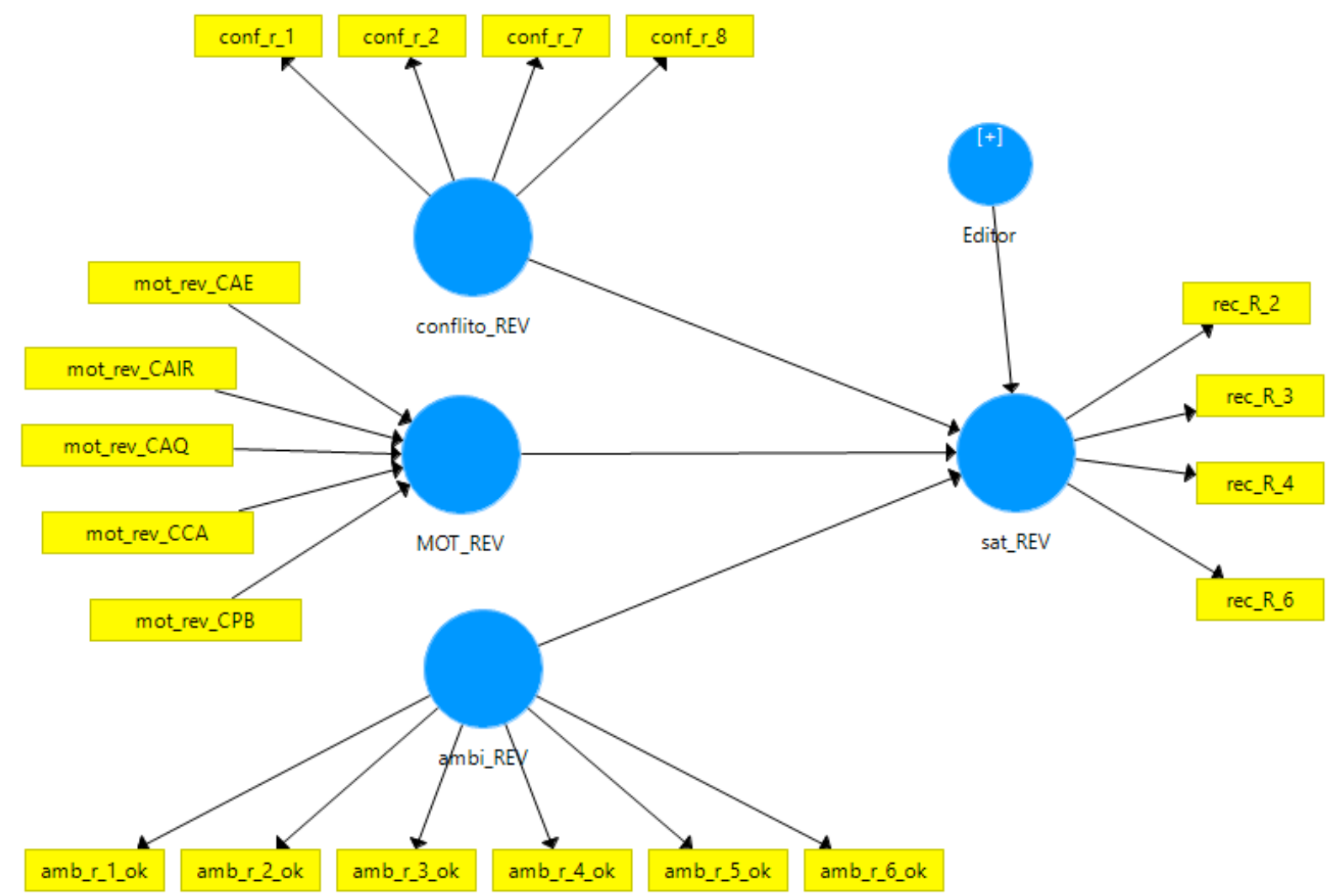

Nota 1: Os indicadores da motivação para atuar como revisor (MOT_REV) são escores fatoriais, que é conhecido como abordagem em duas etapas (Hair Jr. et al., 2016) para a mensuração de VL de segunda ordem.

Nota 2: Modelos com VL de primeira ordem reflexiva e segunda ordem formativa são classificados por Jarvis, Mackenzie, Podsakoff (2003, p.205) como Tipo II.

Nota 3: Na figura há menos indicadores do que no Apêndice 1, porque alguns foram excluídos durante a análise por apresentarem cargas fatoriais muito baixas (menores que 0,35 ).

Figura 2. Modelo estimado por mínimos quadrados parciais (PLS-SEM).

Fonte: Elaborado pelos autores.

Em uma primeira rodada, foi usada a abordagem de repetir os indicadores das VL de $1^{\text {a }}$ ordem na VL de $2^{\text {a }}$ ordem (HairJr., Hult, Ringle, \&Sarstedt, 2016), mas este procedimento se mostrou inadequado por dois motivos:

- Como os indicadores que estão na VL de $1^{a}$ também estavam na VL de $2^{a}$ ordem, todos os pesos fatoriais deram significantes $(\mathrm{p}<0,05)$, isto é, as relações entre a VL de $2^{\mathrm{a}}$ ordem e suas VL de $1^{\mathrm{a}}$ ordem. O que indica a importância relativa das cinco dimensões, mas a dúvida que permaneceu foi se esse resultado era confiável ou ocorreu devido à repetição dos indicadores (endogenia).

- Como CAE tinha mais indicadores que as demais dimensões ( 5 de um total de 17 indicadores repetidos na VL de $2^{\text {a }}$ ordem), seu peso fatorial foi bem maior que o das demais dimensões, isto é, 0,87 enquanto para as demais dimensões foi da ordem de 0,11 a 0,14 .

A partir desses resultados, decidiu-se usar a abordagem em duas etapas (Hair Jr. et al., 2016), que consiste em obter os escores fatoriais para as VL de $1^{\mathrm{a}}$ ordem na $1^{\mathrm{a}}$ etapa e depois usar esses escores como indicadores da VL de $2^{\mathrm{a}}$ ordem ( $2^{\mathrm{a}}$ etapa). Este procedimento foi realizado no SPSS (v.20) por meio da análise de componentes principais de uma VL por vez, com os resultados apresentados na Tabela 3 , sendo considerados adequados do ponto de vista de validade convergente e confiabilidade. 
Tabela 3

Cargas fatoriais das VL de $1^{\text {a }}$ ordem da Motivação para atuar como revisor

\begin{tabular}{lc}
\hline \multicolumn{1}{c}{ mot_rev_CAE } & $\begin{array}{c}\text { cargas } \\
\text { fatoriais }\end{array}$ \\
\hline ac_av_1 & 0,780 \\
ac_av_2 & 0,955 \\
ac_av_3 & 0,897 \\
ac_av_4 & 0,958 \\
ac_av_5 & 0,906 \\
\hline AVE & 0,812 \\
CR & 0,956 \\
\hline & \\
\hline & mot_rev_CCA \\
\hline itens & cargas \\
fatoriais
\end{tabular}

\begin{tabular}{lc}
\hline \multicolumn{2}{c}{ mot_rev_CAIR } \\
\hline itens & $\begin{array}{c}\text { cargas } \\
\text { fatoriais }\end{array}$ \\
\hline ac_av_15 & 0,54 \\
ac_av_16 & 0,689 \\
ac_av_17 & 0,829 \\
ac_av_18 & 0,786 \\
ac_av_19 & excluído \\
\hline AVE & 0,518 \\
CR & 0,807 \\
\hline & \\
\hline & mot_rev_CAQ \\
\hline itens & cargas \\
\hline ac_av_6 & fatoriais \\
ac_av_7 & 0,925 \\
\hline & 0,925 \\
\hline & 0,922 \\
\hline & \\
\hline &
\end{tabular}

\begin{tabular}{lc}
\hline \multicolumn{2}{c}{ mot_rev_CPB } \\
\hline itens & $\begin{array}{c}\text { cargas } \\
\text { fatoriais }\end{array}$ \\
\hline ac_av_11 & excluído \\
ac_av_12 & 0,433 \\
ac_av_13 & 0,841 \\
ac_av_14 & 0,847 \\
\hline AVE & \\
CR & 0,537 \\
\hline
\end{tabular}

Nota 1: Todas as VL apresentaram validade convergente (AVE $>0,5)$, confiabilidade composta $(C R>0,7)$ adequadas (Hair Jr. et al., 2016), bem como unidimensionalidade $\left(1^{\circ}\right.$ autovalor $>1$ e $2^{\circ}$ autovalor $\left.<1\right)$.

Nota 2: Na própria análise de componentes principais foram salvos os escores fatoriais, que depois foram importados para o SmartPLS 3.2.8, para serem usados como indicadores da VL de $2^{\mathrm{a}}$ ordem.

Legenda: mot_rev_CAE = critérios de avaliação externa; mot_rev_CAIR = critérios de apoio e interesse de relacionamento; mot_rev_CAQ = critérios de avaliação qualitativa; mot_rev_CCA = critérios de características do artigo; mot_rev_CPB = critérios de percepção de benefício.

Fonte: elaborado pelos autores.

Com os escores obtidos na $1^{\text {a }}$ etapa foi possível estimar o modelo apresentado na Figura 3 ( $2^{\text {a }}$ etapa), sendo apresentados, a seguir, os resultados da mensuração das VL que estão no modelo estrutural.

Começando pela Motivação para atuar como revisor, observa-se, na Tabela 4, que todos os indicadores apresentaram peso fatorial significante a 5\%, com exceção do mot_rev_CAIR (critérios de apoio e interesse de relacionamento), o que indica que ele não tem importância relativa (quando se usam os cinco indicadores para a mensuração), mas ele tem importância absoluta, já que sua carga fatorial foi igual a 0,46 ( $\mathrm{p}=0,022)$ (Hair Jr. et al., 2016), além disso, em modelos formativos, a remoção de indicadores causa uma alteração na definição do construto, por isso, Bido et al. (2010) recomendam a manutenção de todos os itens, mesmo aqueles que não apresentarem significância estatística. 
Tabela 4

Mensuração do construto formativo (motivação para atuar como revisor)

\begin{tabular}{|c|c|c|c|c|c|}
\hline $\begin{array}{l}\text { VL } 1^{\text {a }} \text { ordem } \\
\text { (escores) }\end{array}$ & $\begin{array}{c}\text { pesos } \\
\text { (outerweights) }\end{array}$ & $\begin{array}{c}\text { valor-p } \\
\text { dos pesos }\end{array}$ & $\begin{array}{c}\text { carga } \\
\text { (outerloading) }\end{array}$ & $\begin{array}{c}\text { valor-p } \\
\text { das cargas }\end{array}$ & VIF \\
\hline mot_rev_CAE & 0,383 & 0,069 & 0,453 & 0,019 & 1,097 \\
\hline mot_rev_CAIR & 0,326 & 0,116 & 0,460 & 0,022 & 1,060 \\
\hline mot_rev_CAQ & $-0,455$ & 0,004 & $-0,260$ & 0,073 & 1,085 \\
\hline mot_rev_CCA & 0,531 & 0,016 & 0,548 & 0,016 & 1,050 \\
\hline mot_rev_CPB & 0,459 & 0,011 & 0,582 & 0,000 & 1,025 \\
\hline
\end{tabular}

Nota 1: Todos os valores de VIF (VariancelnflationFactor - Fator de inflação da variância) são próximos de 1, portanto, praticamente não há multicolinearidade.

Legenda: mot_rev_CAE = critérios de avaliação externa;mot_rev_CAIR = critérios de apoio e interesse de relacionamento;mot_rev_CAQ = critérios de avaliação qualitativa; mot_rev_CCA = critérios de características do artigo; mot_rev_CPB = critérios de percepção de benefício.

Fonte: Elaborado pelos autores.

Como as demais VL do modelo (Figura 2) são reflexivas, foram preparadas as Tabelas 4 e 5, que mostram que a validade convergente e discriminante estão adequadas no nível dos construtos (Tabela 5) e no nível dos indicadores (Tabela 6), assim como a confiabilidade composta, que está acima de 0,7.

Tabela 5

Matriz de correlações entre os construtos do modelo

\begin{tabular}{lccccc}
\hline \multicolumn{1}{c}{ Variável } & $\mathbf{1}$ & $\mathbf{2}$ & $\mathbf{3}$ & $\mathbf{4}$ & $\mathbf{5}$ \\
\hline 1 - Editor & - & & & & \\
\hline 2 - mot_REV & $-0,146$ & - & & & \\
\hline 3 - ambi_REV & 0,123 & $-0,188$ & 0,769 & & \\
\hline 4 - conflito_REV & 0,168 & 0,025 & 0,263 & 0,754 & \\
\hline 5 - sat_REV & $-0,232$ & 0,425 & $-0,319$ & $-0,115$ & $\mathbf{0 , 7 8 4}$ \\
\hline CompositeReliability & - & - & 0,895 & 0,837 & 0,864 \\
\hline AverageVarianceExtracted & - & - & 0,591 & 0,568 & 0,615 \\
\hline
\end{tabular}

Legenda: Editor é uma variável dummy ( 1 = desenvolve ou desenvolveu a atividade de editor de algum periódico acadêmico).sat_REV = satisfação de ser revisor de artigo de periódico acadêmico.mot_REV = Motivação para Aceitar a Função de Revisor. conflito_REV = conflitos de função. ambi_REV = ambiguidade de função.

Nota 1: Os valores na diagonal são a raiz quadrada da AVE (AverageVarianceExtracted Variância média extraída), como esses valores são superiores às correlações entre os construtos (valores fora da diagonal), há validade discriminante (HairJr. et al., 2016).

Nota 2: Correlações iguais ou superiores a $|0,188|$ são significantes a $5 \%$.

Nota 3: A motivação do revisor (MOT_REV) é uma variável latente formativa, por isso não foram apresentados os valores de AVE e CR (CompositeReliability-Confiabilidade composta) para ambas as variáveis.

Fonte: elaborado pelos autores. 
Tabela 6

Matriz de cargas cruzadas para os construtos reflexivos

\begin{tabular}{|c|c|c|c|c|}
\hline & Editor & ambi_REV & conflito_REV & sat_REV \\
\hline editor & 1,000 & 0,123 & 0,168 & $-0,232$ \\
\hline amb_r_1_ok & 0,128 & 0,746 & 0,194 & $-0,338$ \\
\hline amb_r_2_ok & 0,128 & 0,824 & 0,220 & $-0,137$ \\
\hline amb_r_3_ok & 0,104 & 0,598 & 0,277 & $-0,169$ \\
\hline amb_r_4_ok & 0,092 & 0,724 & 0,215 & $-0,132$ \\
\hline amb_r_5_ok & 0,054 & 0,847 & 0,148 & $-0,299$ \\
\hline amb_r_6_ok & 0,075 & 0,845 & 0,220 & $-0,234$ \\
\hline conf_r_1 & 0,104 & 0,230 & 0,605 & $-0,039$ \\
\hline conf_r_2 & 0,045 & 0,297 & 0,737 & $-0,050$ \\
\hline conf_r_7 & 0,191 & 0,168 & 0,694 & $-0,026$ \\
\hline conf_r_8 & 0,171 & 0,193 & 0,939 & $-0,139$ \\
\hline rec_R_2 & $-0,257$ & $-0,265$ & $-0,202$ & 0,775 \\
\hline rec_R_3 & $-0,221$ & $-0,179$ & $-0,096$ & 0,826 \\
\hline rec_R_4 & $-0,085$ & $-0,295$ & 0,038 & 0,816 \\
\hline rec_R_6 & $-0,181$ & $-0,247$ & $-0,124$ & 0,715 \\
\hline
\end{tabular}

Legenda: Editor é uma variável dummy ( 1 = desenvolve ou desenvolveu a atividade de editor de algum periódico acadêmico).sat_REV = satisfação de ser revisor de artigo de periódico acadêmico.ambi_REV = ambiguidade de função. conflito_REV = conflitos de função.

Nota 1: Todas as cargas fatoriais são significantes a $5 \%$.

Nota 2: Todos os indicadores têm cargas fatoriais mais altas em seus respectivos construtos do que em qualquer outro, portantohá validade discriminante no nível dos indicadores (Hair Jr. et al., 2016).

Nota 3: Editor é uma variável dummy (desenvolve ou desenvolveu a atividade de editor de algum periódico acadêmico? $\operatorname{sim} /$ não)

Fonte: elaborado pelos autores.

\subsection{Avaliação do modelo estrutural}

Na Tabela 7são apresentados os resultados do modelo estrutural estimado em três etapas: modelo $1=$ apenas a variável de controle, modelo 2 = modelo completo com a variável de controle, e modelo $3=$ modelo sem a variável de controle.

Descontando o efeito da variável de controle, o modelo explica 17,4\% da variância da satisfação do revisor, o que é considerado um efeito de tamanho média pela classificação de Cohen (1988).

A hipótese $\mathrm{H} 1$ não foi confirmada: conflito não tem relação com a satisfação do revisor, mesmo após controlar o efeito de ser/ter sido editor (nos modelos 3 e $2: \mathrm{f}^{2}=0,004$ e 0,002 , respectivamente, o que significa um efeito igual a zero para fins práticos; e coeficiente estrutural não significante $-p>0,10$ ).

A hipótese $\mathrm{H} 2$ foi confirmada: a motivação para ser revisor tem relação positiva com satisfação do revisor, cujo tamanho do efeito é médio $\left(f^{2}=0,168\right.$ e o coeficiente estrutural padronizado é igual a 0,363 , $\mathrm{p}<0,01)$.

A hipótese H3 foi confirmada: aambiguidade de função tem relação negativa com satisfação do revisor, cujo tamanho do efeito é pequeno para fins práticos $\left(\mathrm{f}^{2}=0,060\right.$ e o coeficiente estrutural padronizado é igual a $-0,222, \mathrm{p}<0,01)$.

Estes resultados são discutidos na próxima seção. 
Tabela 7

Resultados do modelo estrutural

\begin{tabular}{cccccccc}
\hline Modelo & Relação estrutural & Hipótese & $\mathbf{f}^{2}$ & $\begin{array}{c}\text { Coeficiente } \\
\text { estrutural }\end{array}$ & $\begin{array}{c}\text { Erro } \\
\text { padrão }\end{array}$ & Valor-t & Valor-p \\
ajustado
\end{tabular}

Legenda: As abreviações para os nomes dos construtos seguem o que está definido no rodapé da Tabela 5.

$f^{2}=$ tamanho do efeito de Cohen (1988), com a seguinte classificação: $f^{2}=0.02=$ pequeno; $f^{2}=0.15=$ médio;

$\mathrm{f}^{2}=0.35=$ grande .

Nota: Para o modelo 1, R² não teve ajuste.

Fonte: elaborado pelos autores.

\section{Discussão dos Resultados e Conclusões}

O poder explicativo do modelo foi considerado adequado, pela classificação de Cohen (1988). No que se refere à análise das hipóteses, temos a considerar:

- H1. O conflito de função afeta negativamente a satisfação de ser revisor de artigo de periódico acadêmico.

A hipótese não foi validada estatisticamente, analogamente ao que foi obtido por Palomino e Frezatti (2016). As variáveis consideradas na análise, relacionadas a discordar da forma como as coisas são feitas ("Eu tenho que fazer coisas que deveriam ser feitas de forma diferente"), desenvolver a análise sem recursos pessoais para o desenvolvimento ("Eu recebo tarefas sem ter conhecimento E/OU tempo E/OU experiência necessários para completá-las"), desenvolver a análise sem recursos ("Eu recebo uma atribuição sem os materiais e sistemas adequados para executá-lo"), demanda de tempo inadequado ("Eu gasto tempo trabalhando em coisas desnecessárias"), não foram relevantes para indicar que o conflito de funçãoafete negativamente a satisfação dos revisores. Esse resultado fortalece o entendimento de que as questões intrínsecas à participação em uma revisão fazem parte do "pacote", sendo toleradas por quem se propõe a fazê-la. Como um achado, num sentido prático do ponto de vista do editor gerenciando o processo, é valioso, pois permite entender que um revisor não deixaria de aceitar um convite por questões relacionadas ao conflito de função.

- H2. A motivação afeta positivamente a satisfação de ser revisor de artigo de periódico acadêmico.

A hipótese foi validada. Embora os cinco elementos (Avaliação externa, Avaliação qualitativa, Característica do artigo, Percepção de benefício e Apoio e interesse de relacionamento) influenciem a satisfação do revisor, o primeiro elemento é o mais relevante. 
De uma forma resumida, revisar um artigo de um periódico que esteja incluído na lista de A1 do Qualis proporciona mais satisfação do que um B4, por exemplo. Receber o convite para análise de um artigo de periódico que esteja incluído na lista do JRC motiva mais um revisor do que receber o mesmo convite de um periódico que não esteja incluído. Como conclusão, os editores devem comunicar seu sucesso nos vários rankings para atrair não apenas autores mas, principalmente, revisores. Nessa linha de raciocínio, melhoria em ranking poderia levar os revisores a algum ajuste do ponto de vista de atratividade para desenvolver a atividade de revisão de artigos. Finalmente, não foi capturada qualquer melhoria ou posição no ranking, mas, sim, aquelas que mais impactam a vida do pesquisador.

- H3. A ambiguidade de função afeta negativamente a satisfação de ser revisor de artigo de periódico acadêmico.

A hipótese foi validada. As variáveis consideradas levam em conta aspectos que podem ser gerenciados pelos editores e dizem respeito a definições e comunicações destes para os revisores, diminuindo a ambiguidade (Kahnet al.,1964; Fichter, 2010, Montgomery, 2011). Na relação de elementos podemos separar pelo menos dois grupos, quais sejam: o da definição do papel de revisor e sua autonomia ("Está clara a minha autoridade no desenvolvimento da minha tarefa", "Estão claros quais são os objetivos do meu trabalho", "Eu sei que eu distribuo o meu tempo de forma adequada para atender diferentes tarefas", "Eu sei quais são as minhas responsabilidades", "Eu sei exatamente o que é esperado de mim", "Eu tenho clareza sobre o que precisa ser feito") e do produto que se espera da revisão ("Eu sei exatamente o que é esperado de mim", "Eu tenho clareza sobre o que precisa ser feito"). A mensagem que pode ser extraída é que informações que diminuam a ambiguidade e incerteza do que esperar podem proporcionar maior satisfação. A reflexão que fica diz respeito à forma e intensidade de como comunicar.

A experiência como editor de periódico acadêmico, atual ou passada, afeta negativamente a satisfação de ser revisor de artigo de periódico acadêmico. O conjunto de questões não permite identificar a causa em si e as possíveis são de ordem meramente especulativa, podendo ser testadas em outra pesquisa. Uma delas pode significar que o editor ou ex-editor de periódico acadêmico não valorize o seu tempo dedicado a uma revisão por entender que seja uma etapa já vencida na sua trajetória. Pode também entender que desenvolver a análise para outra revista possa ter algum tipo de conflito de interesse a ser evitado.

Em um ambiente em que os periódicos nacionais concorrem com veículos internacionais estruturados, os quais dispõem de relativa maturidade e estrutura editorial amplamente testada, esta pesquisa proporciona contribuições tanto para os editores como para os revisores e autores, que podem aperfeiçoar o processo editorial em termos de qualidade de processo ao direcionar seu foco para o trabalho dos revisores. A pretensão de tratar um tema complexo como a comunicação do conhecimento está ligada ao desafio que ela proporciona ao ambiente acadêmico como um todo. A publicação em si é o principal elemento de avaliação dos pesquisadores e, na sua comunicação, o revisor tem um papel importante como impulsionador ou como bloqueador, tendo o seu reconhecimento verificado de maneira muito limitada. Dessa maneira, entender como dispor e contar com a colaboração dos revisores é vital, para o gerenciamento das atividades editoriais, para os revisores ao proporcionar uma visão de interação do seu trabalho com a perspectiva de gestão dos editores, assim como o potencial questionamento perante eles no que se refere a definições e esclarecimentos que proporcionem maior motivação para participação no processo. Da perspectiva de eliminar inibições, a pesquisa também permite ao editor direcionar seus esforços.

A partir da lógica de que a satisfação do revisor é algo relevante para a manutenção do modelo de ecossistema de comunicação de novos conhecimentos acadêmicos, a pesquisa se volta para esse tema, considerando os elementos inibidores, que são o conflito e a ambiguidade de função, compensados pelo fator estimulador sobre a satisfação, que é motivação do revisor. 
Decorrente da análise de 153 questionários, duas hipóteses foram validadas, quais sejam a de que a ambiguidade de função afeta negativamente a satisfação e de que a motivação afeta positivamente. Além disso, analisado em separado, o fato de um revisor ser ou ter sido editor de periódico acadêmico afeta negativamente a satisfação. Para a amostra considerada, o fato de ser ou de ter sido editor de periódico acadêmico, para o revisor é algo que afeta negativamente a satisfação. As causas dessa percepção não podem ser apontadas neste artigo, pois seriam meras especulações. Contudo, os editores dos periódicos devem estar atentos a esse achado no momento de convidar os revisores.

A ambiguidade de função pode de ser gerenciada por meio de maior clareza na comunicação com os revisores. Isso pode ser praticado por meio de informações disponibilizadas nos portais dos periódicos e mesmo por eventos em que as discussões sobre o tema publicação,

Diferentemente do esperado, o conflito de função não foi validado como elemento que afete negativamente a satisfação, o que não deixa de ser uma informação relevante para a gestão dos editores.

No que se refere às limitações desta pesquisa podemos destacar a dificuldade de dispor de base de dados que pudesse ser utilizada de pronto e referencial sobre os revisores preponderantemente gerados em países com diferentes culturas. Quanto às sugestões para futuras pesquisas recomendamos duas dimensões: aprofundar o entendimento sobre o relacionamento entre os revisores e os editores e pesquisa sobre o que os editores entendem como ético na atuação da função.

\section{Referências}

Anderson, P. (1997). 'Gatekeepers' and the quality of the journal literature: findings from a survey of journal editors into the issue of alleged excessive publication in scholarly and scientific journals. Serials Review, 23(2), pp. 45-57. Doi: https://doi.org/10.1016/S0098-7913(97)90050-2

Bailey, C. D., Hermanson, D. R., \& Louwers, T. J. (2008). An examination of the peer review process in accounting journals. Journal of Accounting Education, 26(2), pp. 55-72. Doi: https://doi. org/10.1016/j.jaccedu.2008.04.001

Berk, J. B., Harvey, C. R., \& Hirshleifer, D. (2017). How to write an effective referee report and improve the scientific review process. Journal of Economic Perspectives, 31(1), pp. 231-244. Doi: https://doi. org/10.1257/jep.31.1.231

Bido, D., Silva, D., Souza, C. A., \& Godoy, A. S. (2010). Mensuração com indicadores formativos nas pesquisas em administração de empresas: Como lidar com a multicolinearidade entre eles?. Administração: Ensino e Pesquisa, 11(2), pp. 245-269. Doi: https://doi.org/10.13058/raep.2010. v11n2.145

Cabral, S.(2018). Autores, pareceristas e editores: tripé do processo de revisão de artigos científicos. Revista Administração de Empresas,58(4), pp. 433-437. Doi: http://dx.doi.org/10.1590/s0034-759020180408

Cohen, J. (1988). Statistical Power Analysis for the Behavioral Sciences. (2nd. ed.). New York: Psychology Press.

Coniam, D. (2012). Exploring reviewer reactions to manuscripts submitted to academic journals. System, 40(4), pp. 544-553. Doi: https://doi.org/10.1016/j.system.2012.10.002

Engers, M., \& Gans, J. S. (1998). Why referees are not paid (enough). The American Economic Review,88(5), pp. 1341-1349. Recuperado de https://www.jstor.org/stable/116875?seq=1

Fichter, C. (2010). A research study of role conflict, role ambiguity, job satisfaction, and burnout among financial advisors. (Tese de Doutorado), Lynn Univeristy.

Fisher, R. T. (1995). Role stress, the type a behaviour pattern, and external auditor job satisfaction and performance.(Dissertação, Master of Commerce and Management), Lincoln University, New Zealand. 
Gilmore, A., Carson, D., \&Perry, C. (2006). Academic publishing: best practice for editors, guest editors, authors and reviewers. European Business Review, 18 (6), pp. 468-478. Doi: https://doi. org/10.1108/09555340610711094

Gregson, T., \& Wendell, J. (1994). Role conflict, role ambiguity, job satisfaction and the moderating effect of job-related self-esteem: a latent variable anal. Journal of Applied Business Research, 10(2), pp.106113. Doi: https://doi.org/10.19030/jabr.v10i2.5944

Jarvis, C. B., MacKenzie, S. B., \& Podsakoff, P. M. (2003). A critical review of construct indicators and measurement model misspecification in marketing and consumer research. Journal of Consumer Research, 30(2), pp. 199-218. Doi: https://doi.org/10.1086/376806

Hair Jr., J. F.,Hult, G. T. M.,Ringle, C. M., \&Sarstedt, M. (2016). A Primer on Partial Least Squares Structural Equation Modeling (PLS-SEM). (2nd. ed.). Thousand Oaks, CA: Sage Publications, Inc.

Harzing, Anne-Wil \& Van der Wal, Ron (2008). Google Scholar: the democratization of citation analysis. Ethics in Science and Environmental Politics, 8(1), pp.61-73. Doi: https://doi.org/10.3354/esep00076.

Kahn, R. L., Wolfe, D. M., Quinn, R. P., Snoek, J. D., \& Rosenthal, R. A. (1964). Organizational stress: studies in role conflict and ambiguity. Oxford, England: John Wiley.Recuperado de https://www.scirp.org/ (S(351jmbntvnsjtlaadkposzje))/reference/referencespapers.aspx? referenceid=1815763

Karadal, H., Ay, U., \& Cuhadar, M. T. (2008). The effect of role conflict and role ambiguity on job satisfaction and organizational commitment: a study in the public and private sectors. The Journal of American Academy of Business, Cambridge, 13(2),pp.195-214.Recuperado de https://www.researchgate.net/ publication/288955910_The_effect_of_role_conflict_and_role_ambiguity_on_job_satisfaction_ and_organizational_commitment_A_study_in_the_public_and_private_sectors

Katz, D., \& Kahn, R. L. (1970). Psicologia social das organizações (2nd. ed.). São Paulo: Atlas.

Little, T. D. (2013). Longitudinal Structural Equation Modeling. New York: The Guilford Press.

Mihalek, E. W. (1989). Role conflict and ambiguity of engineering personnel in a government agency with effects on job related measures.(Tese, Doctor of Education), Temple University, The Faculty of the Graduate School, United States.

Moizer, P. (2009). Publishing in accounting journals: a fair game? Accounting, Organizations and Society, 34(2), pp. 285-304.Doi: https://doi.org/10.1016/j.aos.2008.08.003

Montgomery, M. R. (2011). Does absense of managerial communication negatively influence job satisfaction? A quantitative examination of the correlation between job satisfaction and role conflict and role ambiguity among high-tech employees.(Tese, Doctor of Philosophy), Capella University, David Chapman, Psy.D, Dean, Harold Abel School of Social and Behavioral Sciences.

Oler, D. K., \& Pasewark, W. R. (2016). How to review a paper. Issues in Accounting Education, 31(2), pp. 219-234. Doi: https://doi.org/10.2308/iace-50748

Palomino, M. N., \& Frezatti, F. (2016). Role conflict, role ambiguity and job satisfaction: Perceptions of the brazilian controllers. Revista de Administração, 51(2), pp. 165-181. Doi: https://doi.org/10.5700/ rausp1232

Reuber, A. R. (2010). Strengthening Your Literature Review. Family Business Review, 23(2), pp. 105-108. Doi: https://doi.org/10.1177/0894486510368259

Rigo, A.S.,\& Ventura, A.C.(2019). Por quê e como nos tornamos avaliadores de artigos científicos? Editorial. Revista Organizações \& Sociedade,26(89), pp. 194-199.Doi:https://doi.org/10.1590/19849260890

Ringle, C. M., Wende, S., and Becker, J.-M. 2015. “SmartPLS 3.” Boenningstedt: SmartPLS GmbH. Recuperado de http://www.smartpls.com. 
Rivara, F. P., Cummings, P., Ringold, S., Bergman, A. B., Joffe, A., \& Christakis, D. A. (2007). A comparison of reviewers selected by editors and reviewers suggested by authors. The Journal of Pediatrics, 151(2), pp. 202-205. Doi: https://doi.org/10.1016/j.jpeds.2007.02.008

Rizzo, J. R., House, R. J., \& Lirtzman, S. I. (1970). Role conflict and ambiguity in complex organizations. Administrative Science Quartely, 15(2), pp.150-163. Doi: https://doi.org/10.2307/2391486

Sharma, P. (2016). Editor's note - a year in review, Family Business Review2017, 30(1),pp. 7-10. Doi: https:// doi.org/10.1177/0894486516688809

Singh, J., \& Rhoads, G. K. (1991). Boundary role ambiguity in marketing-oriented positions: a multidimensional, multifaceted operationalization. Journal of Marketing Research, 28(3), pp. 328338. Doi: https://doi.org/10.2307/3172868

Tarrant, T. A. (2008). Role conflict, role ambiguity and job satisfaction of the nurse executive.(Tese, Doctor of Philosophy Degree in Nursing), University of Nevada, Division of Health Sciences, Las Vegas.34(1) pp.72-82. Doi: https://doi.org/10.1097/NAQ.0b013e3181c95eb5

Trzesniak, P., Plata-Caviedes, T.,\& Córdoba-Salgado, O. A. (2012). Qualidade de conteúdo, o grande desafio para os editores científicos,Revista Colombiana de Psicologia, 21(1), pp. 57-78. Recuperado de http://www.scielo.org.co/scielo.php?pid=S0121-54692012000100005\&script=sci_abstract\&tlng=pt

Van De Ven, A. H., \& Johnson, P. E. (2006). Knowledge for theory and practice. Academy of Management Review, 31(4), pp. 802-821. Doi: https://doi.org/10.5465/AMR.2006.22527385

Wright, J.T. C., \& Giovinazzo, R. A. (2000). DELPHI - uma ferramenta de apoio ao planejamento prospectivo. Caderno de Pesquisas em Administração, (1) pp.54-65. Recuperado de https://pt.scribd. com/document/257810335/Wright-Giovinazzo-2000-Delphi-Uma-Ferramenta-de-Apoio-AoPlanejamento-Prospectivo 


\section{Apêndice1. Assertivas utilizadas para mensurar os construtos}

\begin{tabular}{|c|c|c|}
\hline \multicolumn{3}{|c|}{ Opções de resposta: 1 = discordo totalmente a 5 = concordo totalmente } \\
\hline Construto & Itens & Assertivas que capturem o conteúdo \\
\hline \multicolumn{3}{|c|}{ O quanto você concorda que os elementos abaixo são importantes na aceitação de convites para revisar artigos? } \\
\hline \multirow{5}{*}{$\begin{array}{l}\text { Critérios de } \\
\text { Avaliação Externa }\end{array}$} & ac_aval_1_CAE & Ranking do Qualis (priorizando A1, A2, B1 ou B2) \\
\hline & ac_aval_2_CAE & Inclusão na lista da Scielo \\
\hline & ac_aval_3_CAE & Inclusão na lista do JCR \\
\hline & ac_aval_4_CAE & Inclusão na lista da SPELL \\
\hline & ac_aval_5_CAE & Inclusão em outras bases como PROQUEST, REDALIC, Portal CAPES e EBSCO \\
\hline \multirow{2}{*}{$\begin{array}{l}\text { Critérios de } \\
\text { Avaliação } \\
\text { Qualitativa }\end{array}$} & ac_aval_6_CAQ & $\begin{array}{l}\text { Periódicos nacionais que cosidera como relevantes para a } \\
\text { área, independentemente de inclusão em indexadores ou Qualis }\end{array}$ \\
\hline & ac_aval_7_CAQ & $\begin{array}{l}\text { Periódicos internacionais que considera como relevantes para a } \\
\text { área, independentemente de inclusão em indexadores ou Qualis }\end{array}$ \\
\hline \multirow{3}{*}{$\begin{array}{l}\text { Critérios de } \\
\text { Características do } \\
\text { Artigo (Idioma) }\end{array}$} & ac_aval_8_CCA & Artigos escritos em português \\
\hline & ac_aval_9_CCA & Artigos escritos em inglês \\
\hline & ac_aval_10_CCA & Artigos escritos em espanhol \\
\hline \multirow{4}{*}{$\begin{array}{l}\text { Critérios de } \\
\text { Percepção de } \\
\text { Benefício }\end{array}$} & ac_aval_11_CPB & $\begin{array}{l}\text { Aceita fazer a revisão de artigos em periódicos que considere de contribuição } \\
\text { para sua área, independentemente de inclusão em indexadores ou Qualis }\end{array}$ \\
\hline & ac_aval_12_CPB & $\begin{array}{l}\text { Aceita fazer a revisão de artigos em periódicos em que exista algum tipo de } \\
\text { reconhecimento (alguma forma de premiação) }\end{array}$ \\
\hline & ac_aval_13_CPB & Aceita fazer a revisão de artigos em periódicos que considere aprender algo \\
\hline & ac_aval_14_CPB & $\begin{array}{l}\text { Aceita fazer a revisão de artigos em periódicos que considere que pode } \\
\text { ensinar algo }\end{array}$ \\
\hline \multirow{5}{*}{$\begin{array}{l}\text { Critérios de Apoio } \\
\text { e Interesse de } \\
\text { Relacionamento }\end{array}$} & ac_aval_15_CAIR & $\begin{array}{l}\text { Aceita fazer a revisão de artigos em periódicos em que confie no corpo } \\
\text { Editorial }\end{array}$ \\
\hline & ac_aval_16_CAIR & $\begin{array}{l}\text { Aceita fazer a revisão de artigos em função do relacionamento com o corpo } \\
\text { Editorial }\end{array}$ \\
\hline & ac_aval_17_CAIR & Aceita fazer a revisão de artigos em periódico em que queira publicar \\
\hline & ac_aval_18_CAIR & Aceita fazer a revisão de artigos em periódico em que já tenha publicado \\
\hline & ac_aval_19_CAIR & $\begin{array}{l}\text { Por alguma perspectiva tua, a atividade de revisão de artigos acadêmicos } \\
\text { pode te trazer satisfação }\end{array}$ \\
\hline
\end{tabular}




\begin{tabular}{|c|c|c|}
\hline \multicolumn{3}{|c|}{ Opções de resposta: 1 = discordo totalmente a 5 = concordo totalmente } \\
\hline Construto & Itens & Assertivas que capturem o conteúdo \\
\hline \multicolumn{3}{|c|}{ Nas atividades de revisor, como se sente na maior parte dos casos? } \\
\hline \multirow{8}{*}{ Conflito de Função } & $\begin{array}{l}\text { Conflito_func } \\
\text { REVIS_1 }\end{array}$ & Eu tenho que fazer coisas que deveriam ser feitas de forma diferente. \\
\hline & $\begin{array}{l}\text { conflito_func_ } \\
\text { REVIS_2 }\end{array}$ & $\begin{array}{l}\text { Eu recebo tarefas sem ter recursos pessoais (conhecimento E/OU tempo E/OU } \\
\text { experiência) necessários para completá-las }\end{array}$ \\
\hline & $\begin{array}{l}\text { conflito_func } \\
\text { REVIS_3 }\end{array}$ & $\begin{array}{l}\text { Eu tenho que ignorar e até quebrar uma regra ou política, a fim de realizar a } \\
\text { tarefa que me foi confiada }\end{array}$ \\
\hline & $\begin{array}{l}\text { Conflito_func } \\
\text { REVIS_4 }\end{array}$ & $\begin{array}{l}\text { Eu trabalho com dois ou mais grupos de pessoas que atuam de formas } \\
\text { bastante diferentes }\end{array}$ \\
\hline & $\begin{array}{l}\text { Conflito_func } \\
\text { REVIS_5 }\end{array}$ & $\begin{array}{l}\text { Eu recebo pedidos incompatíveis de vários atores (editor e autor) ao mesmo } \\
\text { tempo }\end{array}$ \\
\hline & $\begin{array}{l}\text { Conflito_func } \\
\text { REVIS_6 }\end{array}$ & $\begin{array}{l}\text { Eu faço coisas que são aceitáveis para algumas pessoas e não aceitáveis para } \\
\text { outras }\end{array}$ \\
\hline & $\begin{array}{l}\text { Conflito_func } \\
\text { REVIS_7 }\end{array}$ & $\begin{array}{l}\text { Eu recebo uma atribuição sem os materiais e sistemas adequados para } \\
\text { executá-lo }\end{array}$ \\
\hline & $\begin{array}{l}\text { conflito_func_ } \\
\text { REVIS_8 }\end{array}$ & Eu gasto tempo trabalhando em coisas desnecessárias \\
\hline \multirow{6}{*}{$\begin{array}{l}\text { Ambiguidade de } \\
\text { Função }\end{array}$} & $\begin{array}{l}\text { ambiguidade } \\
\text { REVIS_1_inv }\end{array}$ & Está clara a minha autoridade no desenvolvimento da minha tarefa \\
\hline & $\begin{array}{l}\text { ambiguidade } \\
\text { REVIS_2_inv }\end{array}$ & Estão claros quais são os objetivos do meu trabalho \\
\hline & $\begin{array}{l}\text { ambiguidade_ } \\
\text { REVIS_3_inv }\end{array}$ & $\begin{array}{l}\text { Eu sei que eu distribuo o meu tempo de forma adequada para atender } \\
\text { diferentes tarefas }\end{array}$ \\
\hline & $\begin{array}{l}\text { ambiguidade } \\
\text { REVIS_4_inv }\end{array}$ & Eu sei quais são as minhas responsabilidades \\
\hline & $\begin{array}{l}\text { ambiguidade } \\
\text { REVIS_5_inv }\end{array}$ & Eu sei exatamente o que é esperado de mim \\
\hline & $\begin{array}{l}\text { ambiguidade_ } \\
\text { REVIS_6_inv }\end{array}$ & Eu tenho clareza sobre o que precisa ser feito \\
\hline \multicolumn{3}{|c|}{ O quanto cada assertiva traduz a satisfação como a RECOMPENSA pelo exercício da função tratada como revisor. } \\
\hline \multirow{6}{*}{ Satisfação } & $\begin{array}{l}\text { recompensa_ } \\
\text { REVISOR_1 }\end{array}$ & Retribuição por ter obtido benefício de outrem \\
\hline & $\begin{array}{l}\text { recompensa_ } \\
\text { REVISOR_2 }\end{array}$ & Realização por poder contribuir para o sucesso de outros \\
\hline & $\begin{array}{l}\text { recompensa_ } \\
\text { REVISOR_3 }\end{array}$ & Orgulho de ser envolvido em função da competência \\
\hline & $\begin{array}{l}\text { recompensa_ } \\
\text { REVISOR_4 }\end{array}$ & Valorizado por influenciar pessoas \\
\hline & $\begin{array}{l}\text { recompensa_ } \\
\text { REVISOR_5 }\end{array}$ & Premiações em dinheiro \\
\hline & $\begin{array}{l}\text { recompensa_ } \\
\text { REVISOR_6 }\end{array}$ & Reconhecimento pela capacitação \\
\hline
\end{tabular}

Nota: Os itens da ambiguidade de função são reversos.

Fonte: Conflito de função e ambiguidade de função são de Palomino eFrezatti (2016) e os demais itens foram estruturadosa partir do método Delphi. 